\title{
Recursividade e coordenação em português a partir de sintagmas preposicionais: da prosódia à sintaxe em estudos psicolinguísticos
}

\author{
Recursion and coordination in Portuguese from prepositional phrases: \\ from prosody to syntax in psycholinguistic studies
}

\author{
Nathacia Lucena Ribeiro \\ Aleria Lage \\ Universidade Federal do Rio de Janeiro - Rio de Janeiro - Rio de Janeiro - Brasil
}

\author{
$\diamond$
}

\begin{abstract}
Resumo: A partir de pistas prosódicas, verificadas com experimentos psicolinguísticos de leitura, tem-se aqui o propósito original, por meio dos postulados da Gramática Gerativa, de se mostrar se a prosódia marca a estrutura sintática relativa à Recursividade ou à Coordenação, presente em sintagmas preposicionais (PPs) seguintes a um sintagma verbal no português do Brasil. A curva de pitch, detectada pelo uso da plataforma Praat, permite a análise de sintagmas intonacionais, que possuem características acústicas, como fronteiras, e características linguísticas, como pistas sintáticas (cf. LADD, 1986, 1988). As hipóteses são as de que em frases intonacionais em construções com PPs-adjunto coordenados haja o reset, e em construções com PPs-adjunto recursivos não haja o reset. A ausência do reset corresponde a uma pista prosódica do mecanismo de Recursividade.
\end{abstract}

Palavras-chave: Recursividade; Gramática Gerativa; Sintagma preposicional; Prosódia; Coordenação

\begin{abstract}
From prosodic clues, verified with psycholinguistic reading experiments, we have here the original proposal, under the postulates of Generative Grammar, to show whether the prosody marks syntactic structure related to Recursion or to Coordination, presented in the Prepositional Phrases (PPs) following a Verbal Phrase in Brazilian Portuguese. The pitch curve, detected by the use of the Praat platform, allows an analysis of Intonational Phrases, which have acoustic features, like frontier, and linguistic features, like syntactic clues (cf. LADD, 1986, 1988). The hypotheses are that there is a reset in intonational sentences of constructions with coordinated adjunct PPs and no reset in intonational sentences of constructions with recursive adjunct PPs. The absence of this reset corresponds to a prosodic clue of the recursive mechanism.
\end{abstract}

Keywords: Recursion; Generative Grammar; Prepositional phrase; Prosody; Coordination

\section{Introdução}

Segundo o Programa Minimalista, a Fonologia é um dos responsáveis pela computação da linguagem na Interface Articulatório-Perceptual (Interface A-P). Também na Interface A-P, a Prosódia é responsável pelo mapeamento acústico de estruturas complexas, como as sentenças. Tendo em vista que, no processamento linguístico, a Prosódia mapeia a sintaxe em som estruturado, ela deve demonstrar especialidades no mapeamento do mecanismo de Recursividade.

Testamos, por meio de experimentos psicolinguísticos de leitura, em Português do Brasil (PB), esse postulado, que é considerado muitíssimo importante na Gramática Gerativa - talvez o mais importante deles -: a Recursividade. (cf. CHOMSKY, 1965, 2014; HAUSER, CHOMSKY, FITCH, 2002; NEVINS, PESETSKY, RODRIGUES, 2009a, 2009b; SAUERLAND, 2010; FRANÇA, LAGE, 2014; FRANÇA et al., 2014; MAIA et al., 2015).

A hipótese foi a de que, em sentenças com PPs-adjunto coordenados, haveria o reset das frases intonacionais, e em construções com PPs-adjunto recursivos aconteceria o contrário, isto é, não existiria esse reset. A ausência do reset corresponderia a uma pista prosódica do mecanismo de Recursividade. Para testar nossa hipótese, medimos a 
curva de Pitch nas gravações de frases com PPs-adjuntos recursivos, como nos exemplos a seguir:

(1) O menino pegou o chocolate na caixa na estante no quarto.

E com PPs-adjuntos coordenados:

(2) O menino pegou o chocolate na caixa e na estante e no quarto.

A coleta dos dados linguísticos e a medição acústica da curva de pitch (F0) dos arquivos gravados foram efetuadas pela plataforma Praat. A curva de pitch permite a análise de Intonational Phrases - IPs (Sintagmas Intonacionais), que possuem características acústicas - como fronteiras, pausas e proeminências - e características linguísticas - tais como correspondência à estrutura fonológica e pistas sintáticas (cf. LADD, 1986, 1988). Aqui consideramos os dois tipos de IPs propostos por Ladd (1986): Major Phrase (MP) e Tone Group (TG), sendo que um MP contém TGs. Uma das principais pistas acústicas de fronteira de MP é chamada de declination reset. A cada nova fronteira de MP a declinação é resetada. Quando há Recursividade, há encaixe de estruturas, TGs ou MPs, dentro de um MP ou de um TG e, portanto, não há declination reset.

Aplicamos um experimento em 10 falantes nativos adultos do PB, utilizando 16 pares de frases, cada par com uma frase com estruturas recursivas, tal como em (1), correspondendo a uma com estruturas coordenadas, como em (2), além de 32 frases distratoras.

Os resultados, estatisticamente tratados, mostraram que as frases com estruturas coordenadas apresentaram reset, e naquelas com estruturas recursivas havia ausência de reset, bem de acordo com nossas predições.

Em outras palavras, nossas hipóteses foram confirmadas pelos nossos resultados experimentais: a de que o reset na Prosódia de PPs-adjunto marca a Coordenação; e a hipótese central, de que a ausência desse reset marca a Recursividade, o que significa que de fato a Recursividade existe no PB, e, enquanto Princípio (CHOMSKY, 1981), nas demais línguas naturais, como mostram outros estudos (cf., por exemplo, MAIA et al., 2015).

\section{Pressupostos teóricos}

A Teoria Gerativa propõe que a linguagem, que é exclusiva do homem, tem como característica muito marcante a Recursividade, que é um mecanismo que permite o encaixe de proposições (ideias) e, consequentemente, de estruturas sintáticas, que podem ser sintagmas menores, como sintagmas preposicionais
(Prepositional Phrases - PPs) ou sintagmas maiores, como sintagmas complementizadores (Complementizer Phrases - $C P s$ ), que são as sentenças (cf. CHOMSKY, 1965, 2014; HAUSER, CHOMSKY, FITCH, 2002; NEVINS, PESETSKY, RODRIGUES, 2009a, 2009b; SAUERLAND, 2010; FRANÇA, LAGE, 2014; FRANÇA et al., 2014; MAIA et al., 2015). Sintaxe existe até nos sistemas de comunicação animal, como no canto dos pássaros (cf. VIELLIARD, 1995; SILVA, VIELLIARD, 2006), mas não a Recursividade (cf. FRANÇA, LAGE, 2014). E em qualquer língua a Recursividade está presente, basta coletar os dados atentamente e olhar para eles com clareza (cf. NEVINS, PESETSKY, RODRIGUES, 2009a, 2009b; SAUERLAND, 2010) ${ }^{1}$.

Essas construções sintáticas encaixadas a partir da Recursividade podem ter esse encaixe marcado pela Prosódia, ou seja, pelas características acústicas da língua. Segundo Hauser, Chomsky e Fitch (2002), a Faculdade da Linguagem se divide em dois grandes módulos. Enquanto a Sintaxe e os componentes Forma Fonológica (Phonological Form - PF) e Forma Lógica (Logical Form - LF) constituem a Faculdade da Linguagem Estreita (Faculty of Language Narrow $F L N$ ), a Interface Articulatório-Perceptual (ArticulatoryPerceptual Interface - $A-P)$ e a Interface ConceitualIntencional (Conceptual-Intentional Interface $-C-I$ ) formam a Faculdade da Linguagem Ampla (Faculty of Language Broad - FLB). A Prosódia está na Interface A-P e, portanto, na FLB (cf. HAUSER, CHOMSKY, FITCH, 2002).

Ladd (1986, 1988) trabalhou intensamente para definir com mais clareza o conceito de Intonational Phrase (IP) e seu papel no mapeamento da Recursividade pela Prosódia. O autor, nessas obras, afirma que há uma dificuldade na definição do conceito de IP devido à grande quantidade de diferentes tentativas de definição e à utilização, por todas elas, de termos vagos e mal delimitados. Ainda de acordo com o autor, a literatura traz definições para IP de duas naturezas: com características acústicas ou com características linguísticas. Ainda em Ladd (1986, 1988), o autor decide ficar com os dois aspectos de IP, argumentando, na verdade, que há dois tipos de IP: um definido pela Fonética (baseado na Acústica) e outro definido pela Fonologia (baseado na Linguística). O autor chama o primeiro IP de Major Phrase (MP) e o segundo de Tone Group (TG). E diz que um TG contém unidades menores, que são chamadas

\footnotetext{
Como se observa neste artigo, há vários estudos que mostram a Recursividade como um universal linguístico, e para muitos estudiosos o mais importante, porém há um posicionamento contrário de Daniel Everett, cujo embasamento é bastante questionável (cf. NEVINS, PESETSKY, RODRIGUES, 2009a, 2009b; SAUERLAND, 2010; MAIA et al., 2015).
} 
de Pitch Accent (PA). De forma semelhante, uma sentença pode conter mais de um MP. Esse nível resultante da concatenação de MPs é chamado de Utterance.

Enfim, MPs são IPs maiores que os TGs, e a concatenação de dois TGs resulta em um MP. MPs seriam maiores por terem características acústicas mais bem marcadas e fronteiras mais bem definidas. No entanto, o termo fronteira se apresenta de forma obscura, em se considerando critérios tradicionais como pausa e proeminência. A fronteira de um MP é mais bem definida se levarmos em consideração a declinação (LADD, 1986, 1988). Veja um exemplo de MP e suas subdivisões prosódicas na Figura 1.

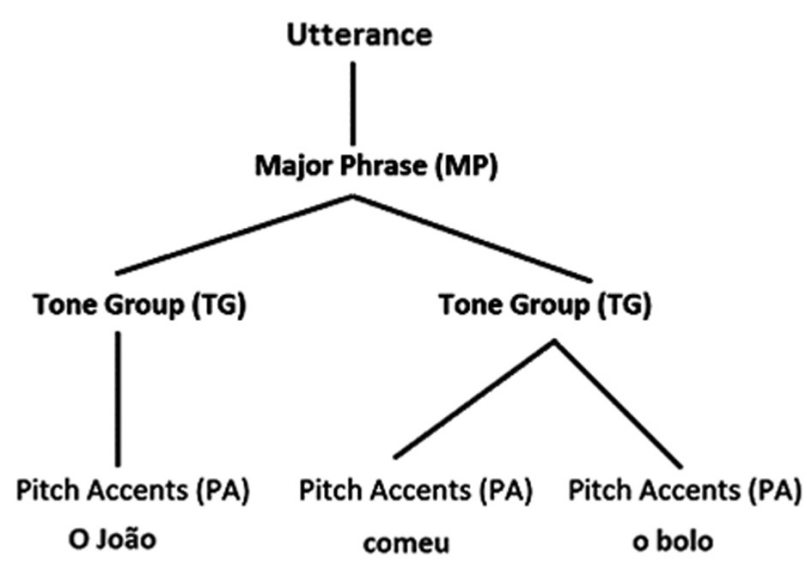

Figura 1. Estrutura dos IPs conforme proposto por Ladd (1986).

Liberman e Pierrehumbert (1984, apud LADD, 1988, p. 530) dizem que "a declinação surge de ocorrências repetidas de downsteps", que é uma queda no pitch logo após um pico de pitch, em cada acento. Cada MP tem a sua própria declinação, e quando um novo MP é introduzido no discurso, a declinação recomeça (resets). Devemos, entretanto, quando analisamos declination reset, levar em consideração que o MP tem um superdomínio - Utterance - com uma declinação própria, à qual a declinação de um MP está sujeita. É o que Ladd $(1986,1988)$ chama de partial reset, ou seja, quando o reset não recomeça a declinação na mesma altura de pitch que a da declinação anterior. É isso que acontece quando um novo MP é introduzido dentro de um Utterance. Observe no exemplo na Figura 2.

A Recursividade prosódica, como proposta por Ladd (1988), é um MP dentro de outro MP ou de um TG; ou um TG dentro de outro TG; não havendo, portanto, ambiente para reset. Assim, ela pode ser testada pela análise de declination (partial) reset, através da medição de pitch de sentenças com estrutura recursiva em oposição a sentenças com estrutura coordenada.

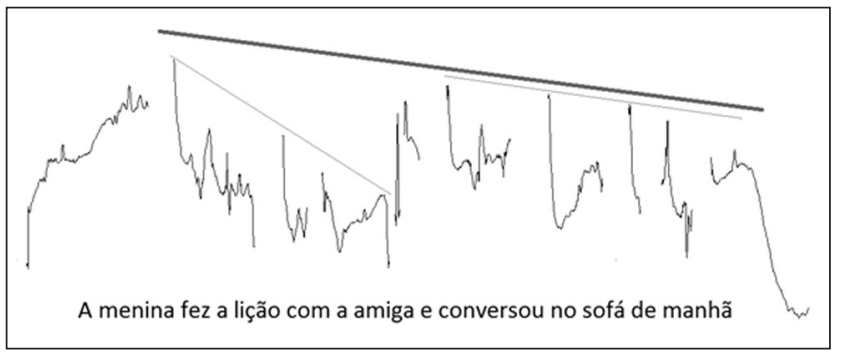

Figura 2. Dois MPs com suas respectivas declinações (linhas finas) sujeitas à declinação de seu superdomínio (linha espessa). Aqui é possível notar o partial reset sofrido pelo segundo MP.

Encaixes de PPs - na Sintaxe - correspondem a encaixes de IPs menores - na Prosódia (Tone Group TP ou Pitch Accent - PA), ou seja, não há declination reset. Quando há Coordenação de sentenças ou de outros constituintes sintáticos, há, na Prosódia, Coordenação de MPs.

\section{Materiais e métodos}

Para testar a organização dos IPs em contextos recursivos, elaboramos um experimento psicolinguístico de leitura em que o sujeito deveria ler em voz alta, e o mais próximo possível da fala natural, frases com PPs adjuntos a Sintagmas Verbais (Verb Phrases - vPs). Estabelecemos duas condições experimentais: frases com encaixe de três PPs-adjunto em estrutura recursiva e frases com encaixe de três PPs-adjunto em estrutura coordenada. Elaboramos 16 sentenças experimentais para cada condição (total de 32 estímulos), além de um total de 32 sentenças distratoras, parte das distratoras com CPs encaixados (subordinadas), por exemplo, como vemos no Quadro 1, a seguir.

Quadro 1. Frases experimentais com estrutura recursiva e frases experimentais com estrutura coordenada. Frases distratoras com estrutura recursiva, frases distratoras com estrutura coordenada e frases distratoras com estrutura subordinada.

\begin{tabular}{|l|l|}
\hline \multicolumn{2}{|c|}{ Estímulos } \\
\hline Estrutura Recursiva & $\begin{array}{l}\text { O síndico largou os papéis na gaveta } \\
\text { no armário na portaria. }\end{array}$ \\
\hline Estrutura Coordenada & $\begin{array}{l}\text { O síndico largou os papéis na gaveta e } \\
\text { no armário e na portaria. }\end{array}$ \\
\hline \multicolumn{1}{|c|}{ Distratores } \\
\hline Estrutura Recursiva & $\begin{array}{l}\text { O síndico largou os papéis da reunião } \\
\text { extraordinária em casa. }\end{array}$ \\
\hline Estrutura Coordenada & $\begin{array}{l}\text { O síndico largou os papéis e as canetas } \\
\text { na gaveta hoje. }\end{array}$ \\
\hline Estrutura Subordinada & $\begin{array}{l}\text { O síndico largou os papéis que usaria } \\
\text { na assembleia do prédio. }\end{array}$ \\
\hline
\end{tabular}


O experimento foi programado na plataforma de apresentação de Estímulos E-Prime 2.0 (Psychology Software Tools, Inc.: Solutions for Research, Assessment, and Education - http://www.pstnet.com/eprime.cfm) e aplicado em 10 sujeitos, falantes nativos do PB, alunos da UFRJ, jovens de idades semelhantes (19 a 28 anos, $M=22,1$ ), sendo a metade de cada sexo, para se afastar qualquer crítica quanto a viés extralinguístico.

Antes de começar o teste, o voluntário assistia a um vídeo, em um laptop Dell, Core i5, com Windows 8, em que aconteceram todos os procedimentos de apresentação de vídeo e de sentenças no treinamento (warm up) e de sentenças experimentais e distratoras, no próprio experimento. Todas as sentenças apareciam em fonte Arial, tamanho 28 e cor branca, em tela preta. O vídeo tinha aproximadamente dez minutos e foi organizado em três partes.

A primeira parte do vídeo consistia na apresentação de cenas, seguidas de frases-comentário. As cenas foram elaboradas de forma que as frases-comentário contemplassem as condições experimentais e os grupos de distratores. Foram gravadas, para essa primeira parte do vídeo, doze cenas, que foram comentadas por frases estruturalmente equivalentes aos nossos estímulos (frases com PPs-adjunto recursivos e frases com PPs-adjunto coordenados) e por frases equivalentes às nossas três categorias de frases distratoras (recursivas, coordenadas e subordinadas). Após cada cena, aparecia uma frase (em fonte Arial, tamanho 28, cor branca e em tela preta) acompanhada do som da leitura da frase, gravada por nós previamente.

A segunda parte do vídeo consistia em um treinamento quanto à leitura das frases, com comentário quanto às cenas, que foram nove, a fim de apenas exemplificar, o que já é de domínio do falante: diferenças estruturais e de leitura entre frases recursivas e coordenadas, considerando aí frases com estruturas equivalentes às de nossos estímulos. Após cada cena, de forma semelhante à primeira parte do vídeo, aparecia uma frase, mas, dessa vez, o sujeito experimental era instruído a ele próprio realizar as leituras. Também nessa parte do treinamento foram utilizadas frases correspondentes às duas categorias de estímulos e às três categorias de distratores.

Em seguida, começávamos a terceira parte do vídeo, que consistia na apresentação sequencial de telas, cada qual com uma frase, que o sujeito deveria ler em voz alta. Foram elaboradas cinco frases para essa parte do treinamento, cada qual pertencente a uma das categorias de estímulos ou de distratores, todos pseudoaleatorizados.

Após o treinamento completo, iniciávamos o experimento, quando então as sentenças experimentais juntamente com as distratoras eram rigorosamente aleatorizadas pela programação computacional, de modo que ela gerasse uma ordem diferente de sentenças para cada novo voluntário. Assim, eram apresentadas 64 frases (32 estímulos e 32 distratores) uma a uma, logo após uma tela com uma cruz de fixação para cada nova frase. A função dessa cruz na tela é eliminar resquícios de memória relativos à computação linguística da frase anterior e de imagem da tela anterior.

O sujeito tinha sido instruído a ler cada frase duas vezes em voz alta, e sem leitura prévia. Caso ele achasse que durante a leitura da frase havia errado na leitura, ele devia retomar a leitura a partir do início da frase. Após a tarefa de leitura, o próprio sujeito passava à próxima tela apertando qualquer tecla do teclado, quando então, antes da nova frase, aparecia uma cruz de fixação.

Todas as leituras foram gravadas em um iPad (Apple, iPad 4, iOS 7.1.2), por meio do aplicativo de gravação Recorder Plus HD (Turbokey Studio - http://turbokey. dyndns.org). O iPad era posicionado ao lado do computador, ficava com a tela desligada e coberta pela capa.

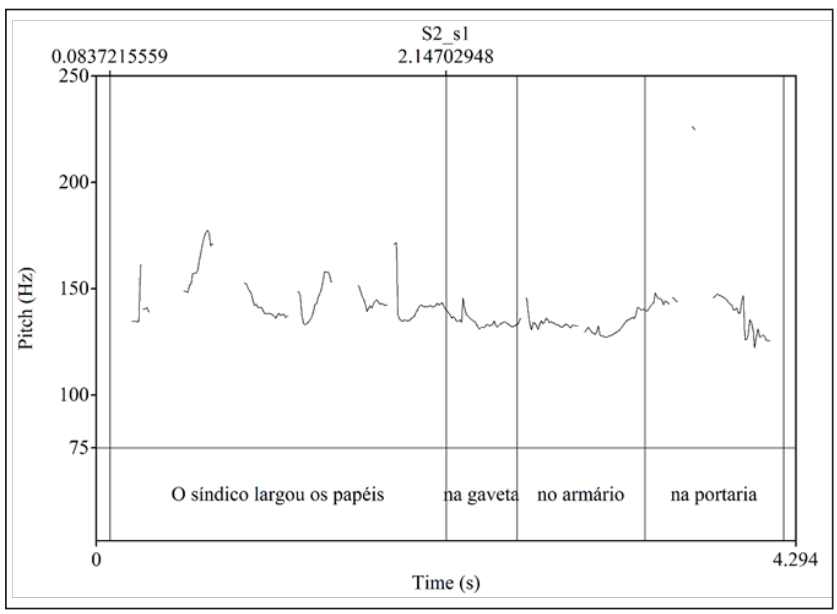

Figura 3. Pitch Track da gravação do sujeito 2 realizando prosodicamente nosso estímulo 1 .

As gravações foram inseridas na plataforma Praat: doing Phonetics by Computer (de Paul Boersma e David Weenink), onde foi possível gerar as curvas de pitch referentes às leituras dos estímulos, referentemente a cada voluntário. Usamos um range médio de $225 \mathrm{~Hz}$ para mulheres $(75 \mathrm{~Hz}$ a $300 \mathrm{~Hz})$ e de $115 \mathrm{~Hz}$ para homens $(75 \mathrm{~Hz}$ a $180 \mathrm{~Hz})$. Cada curva foi analisada quanto à sua declinação, pausa e proeminência, além da duração da vogal tônica quando necessária.

A predição era a de que a estrutura recursiva sintática fosse igualmente recursiva na organização prosódica dos IPs, ou seja, o encaixe de um PP equivaleria ao encaixe de um TG dentro do mesmo MP, não apresentando, portanto, declination reset, por não apresentar fronteira entre MPs em uma mesma sentença, conforme proposto por Ladd (1986). 
Sentenças com coordenação, em contrapartida, apresentariam fronteira de MP. Em outras palavras, sentenças não encaixadas, como as coordenadas, geram novos MPs, e, consequentemente, declination reset.

\section{Resultados e discussão}

Os resultados estão de acordo com as predições. A totalidade $(100 \%)$ das frases lidas por todos os falantes testados, quando com estruturas coordenadas em forma de PP-adjunto, apresentaram declination reset, o que, como já explicamos, parece uma marcação prosódica para a Coordenação. E a maioria $(62,47 \%)$ das frases lidas por todos os falantes testados, quando com estruturas recursivas em forma de PP-adjunto, não apresentaram um declination reset, e essa ausência de reset é marca prosódica de Recursividade. Os resultados foram tratados estatisticamente, o que significa que esses percentuais possuem relevância estatística.

As ocorrências de declination reset foram contadas para cada sujeito. Calcularam-se as proporções para o número de ocorrência de reset para cada sujeito, sendo 1 (um) o valor para cem por cento, e 0 (zero) o valor para nenhuma ocorrência $(\mathrm{n}=16$ por condição). Foi aplicado cálculo estatístico ANOVA (The Analysis of Variance - A

Gráfico 1. Média das ocorrências de reset entre os falantes, apresentadas por condição.

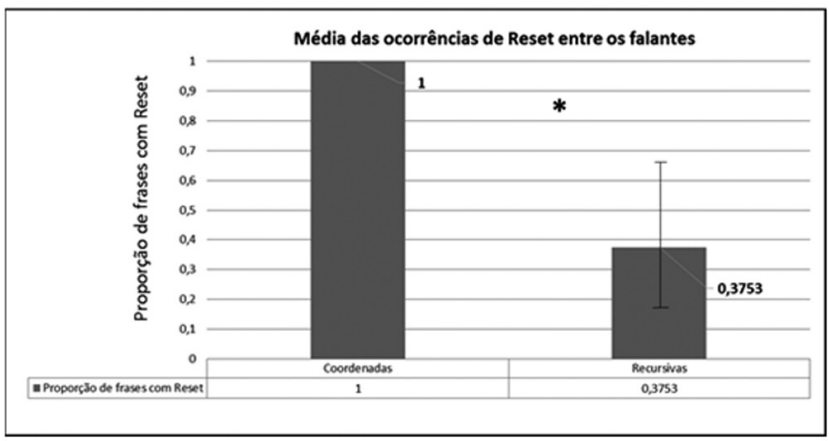

Gráfico 2. Ocorrência de declination reset por condição.

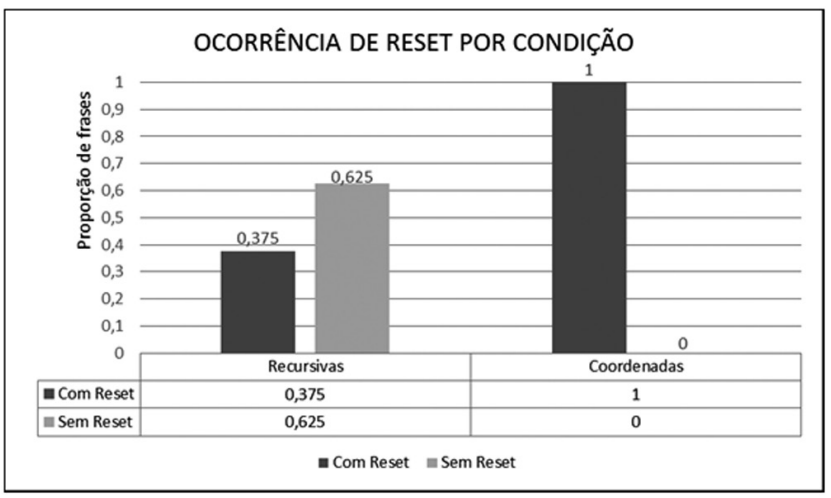

Análise de Variância), e esse tratamento estatístico gerou um $\mathrm{P}=0,000000000155$. Esse valor de $p$ demonstra a relevância estatística dos nossos resultados.

Aplicamos ainda um T-test, a fim de avaliar a relevância da nossa hipótese e obtivemos $\mathrm{P}=0,0000144$. Calculamos então uma média da proporção de ocorrências de reset entre os falantes por condição.

Vemos, no lado esquerdo do Gráfico 1, que o total das frases coordenadas apresentaram reset, em oposição a menos de $37,53 \%$ das frases recursivas, que estão representadas na coluna à direita. $\mathrm{E}$ foi realizado ainda um cruzamento estatístico, com o propósito de comparar as realizações de reset dentro das condições, conforme se observa no Gráfico 2.

Podemos afirmar que nossas teses estão sustentadas pelos resultados e pela significância estatística, o que significa que, de fato, o reset corresponde à Coordenação; e a ausência do reset, à Recursividade.

Mas podemos pensar ainda em o que levou os falantes testados, ainda que esses valores não tenham relevância estatística, a lerem PPs-adjunto recursivos como coordenados.

Analisando esses resultados, verificamos outros achados (Gráficos 3 e 4).

Gráfico 3. O percentual de frases recursivas lidas como coordenas e com inclusão da conjunção e é igual a 33,3\%.

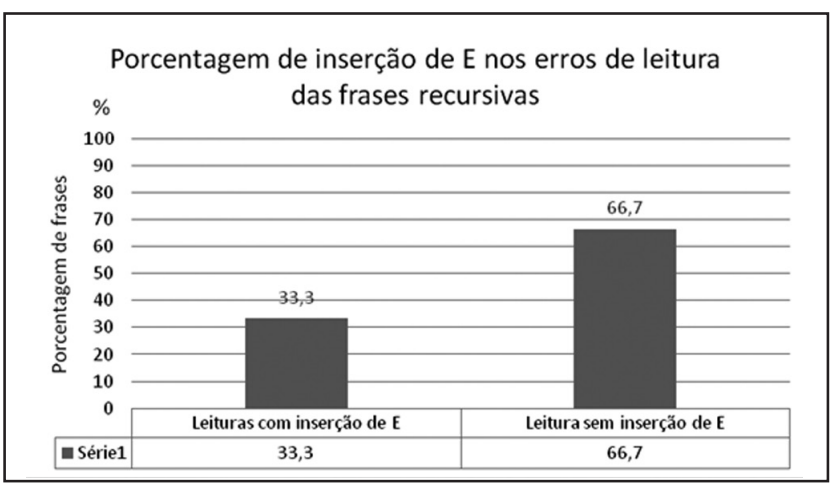

Gráfico 4. Quantidade (n) de frases recursivas que apresentaram erros de leitura. Este gráfico pode ser comparado ao Gráfico 3.

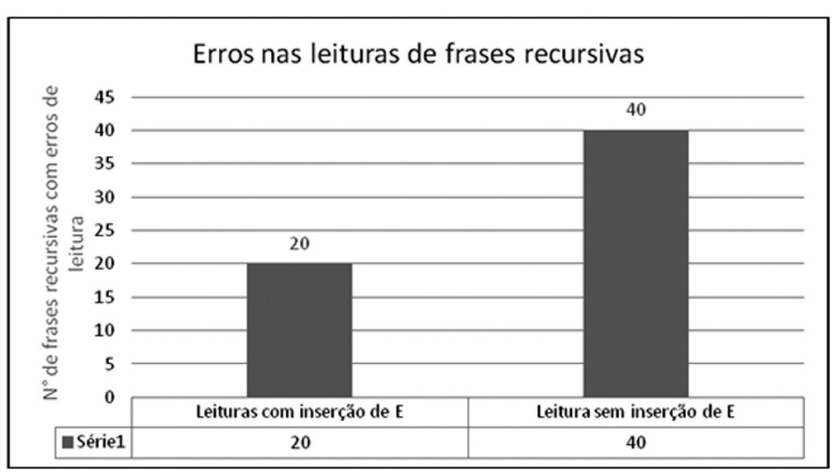


Entendemos que $37,53 \%$ das frases recursivas eram lidas como coordenadas, muito possivelmente porque os falantes fizeram uma releitura, podendo isso ser considerado literalmente, de modo que os PPs-adjunto encaixados, recursivos, eram lidos como coordenados. A inserção da conjunção $e$ após os PPs-adjunto, conjunção essa que não existia na frase e era inserida pelo falante deixa clara a leitura e computação de uma estrutura coordenada. Por isso o reset.

Podemos também buscar uma explicação para as demais frases com estruturas recursivas lidas como com estruturas coordenadas, que perfazem $66,7 \%$ delas. A Coordenação não se mostra através da conjunção $e$, mas se faz clara através da enumeração dos PPs-adjunto. Enumeração mesmo sem a conjunção e também causa reset em $\mathrm{PB}$. Por isso o reset.

Desta forma, inferimos que, se não houvesse essa reinterpretação dos falantes, não haveria reset $\mathrm{em}$ $100 \%$ das frases com estruturas recursivas. Para entender melhor isso, precisamos fazer mais testes. E deixemos claro que, de todo modo, confirmamos nossas hipóteses.

\section{Conclusão}

Por fim, ratificamos que, diante dos resultados do experimento de psicolinguística de leitura que realizamos, por meio do qual testamos sentenças com PPs-adjunto recursivos ou coordenados, pudemos confirmar nossas predições. Na leitura, a cada PP-adjunto coordenado havia um declination reset, que marca prosodicamente a Coordenação. Vemos então, a partir de resultados experimentais com relevância estatística, a Prosódia demarcando o PP-adjunto coordenado. Ou seja, no processamento linguístico, a Prosódia dá a pista sintática para a introdução de um PP-adjunto coordenado. Por outro lado, a ausência do declination reset é pista sintática para a ocorrência de um PP-adjunto recursivo.

Em outras palavras, a estrutura prosódica respondeu ao mecanismo da recursividade de forma satisfatória, comportando, em sua organização de IPs, novos TGs encaixados sem que houvesse a introdução de um novo MP. Isso vai ao encontro da universalidade desse mecanismo, conforme proposto por Chomsky (1981) e Hauser, Chomsky e Fitch (2002), quando se demonstra, de forma original, a existência desse fenômeno em mais uma língua, no $\mathrm{PB}$.

Mas queremos ainda saber mais. Entender melhor esse processo de reinterpretação da leitura das estruturas recursivas enquanto coordenadas. Muito possivelmente pelo fato da frequência muito maior de estruturas coordenadas se comparadas às recursivas, em se tratando de PPs-adjunto.
Novos experimentos deverão ser conduzidos para testar a compreensão dos sintagmas intonacionais como mapeamento sintático, quando então poderemos testar se a leitura de forma numerada (com um reset em cada PP) serve ou não de mapeamento prosódico para o mecanismo de Recursividade.

\section{Referências}

BOERSMA, P.; WEENINK, D. Praat: doing Phonetics by computer. Available from: <http://www.fon.hum.uva.nl/praat/> (access: July 20, 2013.

CHOMSKY, N. Minimal recursion: exploring the prospects. In: ROEPER, T.; SPEAS, M. Recursion: complexity in cognition. Berlim: Springer, 2014 (2012). (Studies in Theoretical Psycholinguistics, 43). Available from: <http://www.letras. ufrj.br/poslinguistica/recursion/papers/2-noam-chomsky.pdf $>$ (access: July 15, 2013.

CHOMSKY, N. Lectures on government and binding: the Pisa lectures. Dordrecht: Foris, 1981. 371 p. (Studies in Generative Grammar, 9).

CHOMSKY, N. Aspects of the theory of syntax. 10. ed. Cambridge, MA: The MIT Press, 1965. 251 p.

FRANÇA, A. I.; LAGE, A. C. Caminhando com os fundamentos da Gramática Gerativa. Agosto 2014 (manuscrito).

FRANÇA, A. I.; CARVALHO, A. S. L.; LAGE, A. C.; PINTO, M. S. The acquisition of coordination of PPs and the acquisition of recursion of PPs: how to fare the development of these computations? Revista da ABRALIN, 2014 (artigo submetido).

HAUSER, M. D.; CHOMSKY, N.; FITCH, W. T. The faculty of language: What is it, who has it, and how did it evolve? Science, Washington: Highwire Press, v. 298, p. 1569-1579, November 22, 2002.

LADD, D. R. Intonational phrasing: the case for recursive prosodic structure. Phonology, Cambridge: Cambridge University Press, v. 3, p. 311-340, 1986.

LADD, D. R. Declination reset and the hierarchical organization of utterances. Journal of the Acoustical Society of America, Melville, NY: Acoustical Society of America, v. 84, p. 530-544, 1988. http://dx.doi.org/10.1121/1.396830

LIBERMAN, M; PIERREHUMBERT, J. Intonational invariance under changes in pitch range and length. In: ARONOFF, M.; OERHLE, R. (Ed.). Language Sound Structure. Cambridge, MA: MIT Press, 1984. p. 157-233.

MAIA, M. A. R.; FRANÇA, A. I.; LAGE, A. C.; MANHÃESGESUALDI, A.; SILVA, C. O. The comprehension of PP recursion and coordination in Karajá and in Portuguese. In: ROEPER, T.; MAIA, M. A. R.; NEVINS, A. Recursion in Brazilian languages and beyond. Cambridge: Cambridge University Press, 2015 (in press).

NEVINS, A.; PESETSKY, D.; RODRIGUES, C. Pirahã exceptionality: a reassessment. Language, Washington: Linguistic Society of America, v. 85, n. 3, p. 671-681, 2009.

NEVINS, A.; PESETSKY, D.; RODRIGUES, C. Pirahã exceptionality: a reassessment. Language, Washington: Linguistic Society of America, v. 85, n. 2, p. 355-404, 2009. 
SAUERLAND, U. Experimental evidence for complex syntax in Pirahã. 2010, ms. Available from: <http://www.letras.ufrj.br/ poslinguistica/recursion/papers/7-uli-sauerland.pdf $>$ (access: July 15, 2013.

SILVA, M. L.; VIELLIARD, J. Entropy calculations for measuring birdsong diversity: the case of the White-vented
Violetear (Colibri Serrirostris). SAZU, Ljubljana, Eslovênia: Slovenska Akademija Znanosti in Umetnosti, v. 47, p. 37-49, 2006.

VIELLIARD, J. Phylogeny of bioacoustical parameters in birds. Bioacoustics, v. 6, 1995, p. 171-175. http://dx.doi.org/ 10.1080/09524622.1995.9753283

\title{
APÊNDICE
}

\author{
R: Estímulos recursivos \\ C: Estímulos coordenados \\ DR: Distratores recursivos \\ DC: Distratores coordenados \\ DS: Distratores com sentenças encaixadas (subordinadas)
}

\begin{tabular}{|c|c|c|}
\hline \multirow{2}{*}{1} & $\mathbf{R}$ & O síndico largou os papéis na gaveta no armário na portaria. \\
\hline & C & O síndico largou os papéis na gaveta e no armário e na portaria. \\
\hline \multirow{2}{*}{2} & $\mathbf{R}$ & O advogado guardou as joias no cofre na sala na empresa. \\
\hline & C & O advogado guardou as joias no cofre e na sala e na empresa. \\
\hline \multirow{2}{*}{3} & $\mathbf{R}$ & O empresário assinou os contratos no cartório no edifício no centro. \\
\hline & C & O empresário assinou os contratos no cartório e no edifício e no centro. \\
\hline \multirow{2}{*}{4} & $\mathbf{R}$ & O médico carimbou as receitas na mesa na recepção no hospital. \\
\hline & C & O médico carimbou as receitas na mesa e na recepção e no hospital. \\
\hline \multirow{2}{*}{5} & $\mathbf{R}$ & A estilista bordou as roupas no manequim na loja na fábrica. \\
\hline & C & A estilista bordou as roupas no manequim e na loja e na fábrica. \\
\hline \multirow{2}{*}{6} & $\mathbf{R}$ & O repórter comentou os filmes na matéria no programa na rádio. \\
\hline & C & O repórter comentou os filmes na matéria e no programa e na rádio. \\
\hline \multirow{2}{*}{7} & $\mathbf{R}$ & A moça levou os talheres no guardanapo no prato na bandeja. \\
\hline & C & A moça levou os talheres no guardanapo e no prato e na bandeja. \\
\hline \multirow{2}{*}{8} & $\mathbf{R}$ & O atleta exibiu as medalhas na arquibancada na quadra na escola. \\
\hline & C & O atleta exibiu as medalhas na arquibancada e na quadra e na escola. \\
\hline \multirow{2}{*}{9} & $\mathbf{R}$ & O garçom serviu as bebidas no bar na piscina no clube. \\
\hline & C & O garçom serviu as bebidas no bar e na piscina e no clube. \\
\hline \multirow{2}{*}{10} & $\mathbf{R}$ & O técnico instalou os alarmes no portão na rampa na garagem. \\
\hline & C & O técnico instalou os alarmes no portão e na rampa e na garagem. \\
\hline \multirow{2}{*}{11} & $\mathbf{R}$ & O marceneiro serrou as tábuas na escada na casa no condomínio. \\
\hline & C & O marceneiro serrou as tábuas na escada e na casa e no condomínio. \\
\hline \multirow{2}{*}{12} & $\mathbf{R}$ & O garoto desenhou as figuras na folha na revista na escola. \\
\hline & C & O garoto desenhou as figuras na folha e na revista e na escola. \\
\hline \multirow{2}{*}{13} & $\mathbf{R}$ & A aluna achou as canetas no estojo no bolso na mochila. \\
\hline & C & A aluna achou as canetas no estojo e no bolso e na mochila. \\
\hline \multirow{2}{*}{14} & $\mathbf{R}$ & O contador calculou os prejuízos no balcão no escritório na firma. \\
\hline & C & O contador calculou os prejuízos no balcão e no escritório e na firma. \\
\hline \multirow{2}{*}{15} & $\mathbf{R}$ & O doente pegou os remédios na cartela na caixa na estante. \\
\hline & C & O doente pegou os remédios na cartela e na caixa e na estante. \\
\hline \multirow{2}{*}{16} & $\mathbf{R}$ & O ator recebeu aplausos no corredor no camarim no teatro. \\
\hline & C & O ator recebeu aplausos no corredor e no camarim e no teatro. \\
\hline 17 & DC & O síndico largou os papéis e as canetas na gaveta hoje. \\
\hline 18 & DC & O advogado guardou as joias e o testamento no cofre ontem. \\
\hline 19 & DC & O empresário assinou os contratos e o comunicado no salão agora. \\
\hline 20 & DC & O médico carimbou as receitas e a alta no hospital de manhã. \\
\hline 21 & DC & A estilista bordou as roupas e as bolsas no manequim feminino. \\
\hline
\end{tabular}




\begin{tabular}{|c|c|c|}
\hline 22 & DC & O repórter comentou os filmes e as fotos na rádio esta tarde. \\
\hline 23 & DC & A moça levou os talheres e os copos na bandeja até a mesa. \\
\hline 24 & DC & O atleta exibiu as medalhas e o troféu na escola com orgulho. \\
\hline 25 & DC & O garçom serviu as bebidas e a porção na piscina para o hóspede. \\
\hline 26 & DC & O técnico instalou os alarmes e as câmeras na garagem essa semana. \\
\hline 27 & DC & O marceneiro serrou as tábuas e as toras na mansão ontem. \\
\hline 28 & DR & O garoto desenhou as figuras dos personagens dos quadrinhos na folha. \\
\hline 29 & DR & A aluna achou as canetas coloridas da irmã na mochila. \\
\hline 30 & DR & O contador calculou os prejuízos abusivos do mês na drogaria. \\
\hline 31 & DR & O doente pegou os remédios para dor na cartela do médico. \\
\hline 32 & DR & O ator recebeu os aplausos efusivos da plateia no palco. \\
\hline 33 & DR & O síndico largou os papéis da reunião extraordinária em casa. \\
\hline 34 & DR & O advogado guardou as joias caras da viúva no banco. \\
\hline 35 & DR & O empresário assinou os contratos com os clientes estrangeiros hoje. \\
\hline 36 & DR & O médico carimbou as receitas do remédio controlado importado. \\
\hline 37 & DR & A estilista bordou as roupas sob medida ontem no manequim. \\
\hline 38 & DR & O repórter comentou os filmes dos ouvintes polêmicos no programa. \\
\hline 39 & DS & A moça levou os talheres que estavam faltando na mesa. \\
\hline 40 & DS & O atleta exibiu as medalhas que ganhou no torneio interno. \\
\hline 41 & DS & O garçom serviu as bebidas que os clientes especiais pediram. \\
\hline 42 & DS & O técnico instalou os alarmes que eu te falei no outro dia. \\
\hline 43 & DS & O marceneiro serrou as tábuas que vieram das árvores de ipê. \\
\hline 44 & DS & O garoto desenhou as figuras que tinha visto na revista. \\
\hline 45 & DS & A aluna achou as canetas que ganhou da mãe de aniversário. \\
\hline 46 & DS & O contador calculou os prejuízos que a empresa teve esse ano. \\
\hline 47 & DS & O doente pegou os remédios que precisava para melhorar depressa. \\
\hline 48 & DS & O ator recebeu os aplausos que merecia pela peça de hoje. \\
\hline 49 & DS & O síndico largou os papéis que usaria na assembleia do prédio. \\
\hline
\end{tabular}

Recebido: 31 de agosto de 2014

Aprovado: 21 de outubro de 2014

Contatos: nathacia.lucena@gmail.com aleria@gmail.com 